\title{
Editorial on Intergenerational learning and digital technologies: New perspectives from research
}

\author{
Don Passey
}

Published online: 6 July 2014

(C) Springer Science+Business Media New York 2014

\section{Digital technologies and lifelong learning}

Learning has not only been considered for some time as a lifelong endeavour (see, for example, Cotton 1998), but also as a necessary lifelong endeavour (see, for example, Hoznan 2009). Uses of digital technologies are supporting these endeavours; digital technologies enable wider access (described, for example, by the United States Department of Education, n.d.), easier access (illustrated, for example, by JISC 2012) and more focused access (detailed, for example, by Hall 2005) to lifelong learning.

Although learning for individuals is now conceived as being lifelong in terms of practice and needs, nevertheless, learning is often still structured through a series of institutions, concerned with supporting certain age groups or phases of learning need. So, schools support those from perhaps 4 to 18 years of age; universities and further education colleges support those from about 18 to 25 years of age (although increasingly this range is lengthening and can include those up to 70 years of age or beyond); workplaces support learners often within an age range from 18 to 65 years; and retirement facilities support learners who might be aged from say 55 years upwards. Within these 'institutions', a mixture of old and young people are often encountered: learners and teachers; learners and tutors; apprentices and 'masters'; supporters and retirees. In any of these 'institutions', digital technologies are likely to be found; and increasingly digital facilities are being used to support learning practices. Yet those who either have the most time to explore applications of emerging and digital technologies to learning or have the most experience with using digital technologies to support their personal needs are often younger people; but those who have most experience of subject or practical needs, or supporting learning in specific or general ways, are often older people. So how can the development of appropriate practices and models to support a shared evolution, enabling experience and expertise of both digital technologies and learning to be brought together for a common good, be considered and put into place?

D. Passey $(\bowtie)$

Centre for Technology Enhanced Learning, Department of Educational Research, Lancaster University,

Lancaster LA1 4YD, UK

e-mail: d.passey@lancaster.ac.uk 


\section{The papers in this special edition}

Five papers in this special edition explore different but important and complementary aspects of this key question. They are presented in this volume in the order of 'age institutions' that involve and develop intergenerational learning practices: schools; universities; workplaces; and retirement facilities. The first (Passey 2014) investigates a sharing initiative in schools - where students are given opportunity to lead teachers and managers, providing them through advice and support to develop appropriate teaching and learning practices with digital technologies that are new to them. The second (Lyashenko and Frolova 2014) explores shared intergenerational practices in a university context using a digital technology medium - mixing the old and the young, but importantly using understandings from psychological and sociological lessons from research to support mixed aged groups in developing digital technology practices for their teaching and learning. The third (Ypsilanti et al. 2014) explores how potential intergenerational sharing mechanisms in a workplace context might use a medium of interactive games - looking at how these games might play an important role in developing practices to support lifelong sharing. The fourth (Räisänen et al. 2014) looks at intergenerational developments for the workplace - identifying fundamental specific requirements for interactive games that would positively support intergenerational learning. The fifth (Tatnall 2014) looks at intergenerational experiences in retirement - exploring models enabling the young to support the old with continued education and learning.

\section{What is new from this research?}

These papers highlight details in specific contexts not previously identified in research. For example, how an initiative in schools enabled students to contribute to the community, rather than just receiving from it, so that those students became active contributors to, as well as receivers from, the educational system (Passey 2014). The papers look at specific models of practice that are seen to be successful and useful. For example, how practices offering older people the means to keep in touch with family, to obtain health or financial information, or about entertainment or education, supported opportunities for intergenerational cooperation with children coaching grandparents (Tatnall 2014), and how an initiative involved students as digital leaders in secondary schools, where some students had not been involved previously in other leadership or school-wide activities (Passey 2014). The papers indicate how research has been brought to bear to support or explore those practices. For example, how a development has considered and accommodated the importance of being aware of specific differences in human development at particular ages to support intergenerational learning, and how a better understanding of psychological factors such as motivation, creativity and intelligence can allow levels of intergenerational integration and knowledge creation to develop more positively (Lyashenko and Frolova 2014), and how a study on older people's uses of digital education for learning in formal and informal settings explored these through a socio-technical framework based on actornetwork theory (Tatnall 2014). The papers indicate how building elements of a longer lifelong concern and endeavour can result in positive outcomes. For example, how 
using a learning management system to support professional development through collaboration of adults and young learners in universities led to identifiable outcomes (Lyashenko and Frolova 2014). The papers highlight research and development gaps and needs. For example, how a study is looking at shared learning through the use of serious games, accounting for differences in learning style and the structure of learning if intergenerational participation is to arise from playing a game, especially as examples of games designed to facilitate intergenerational learning are 'scarce', with no examples in most countries within the European Union (Ypsilanti et al. 2014). The papers consider developing technologies to support these research and development gaps and needs. For example, how a study is investigating the requirements for an interactive game, finding suitable contexts, interventions and mechanisms to allow the design of such a game, to help raise awareness of intergenerational learning, and at the same time allow individuals to practice related skills, while considering also the need for it to be easily adapted to different countries and cultures (Räisänen et al. 2014).

The purpose of this special edition is to bring together a number of papers that offer new and additional insights, consider contexts in which intergenerational learning and digital technologies are being integrated, and to enable and encourage a wider and longer-term discussion. These papers highlight the need for continued study, and indicate clearly some of the gaps where future studies can further support practice and policy in this area.

\section{References}

Cotton, K. (1998). Education for Lifelong Learning: Literature Synthesis. Research You Can Use: Lifelong Learning Series, Booklet 5. Portland, OR: Northwest Regional Education Lab.

Hall, A. (2005).Community Access to Lifelong Learning (CALL) Evaluation - Final Report. Glasgow: Hall Aitken.

Hoznan, D. (2009). Key competences for the development of lifelong learning in the European Union. European Journal of Vocational Training, 46, 196-207.

JISC. (2012). Learning in a Digital Age: Extending higher education opportunities for lifelong learning. Bristol: JISC.

Lyashenko, M., \& Frolova, N. (2014). LMS projects: a platform for intergenerational e learning collaboration. Education and Information Technologies. doi:10.1007/s10639-014-9333-9.

Passey, D. (2014). Intergenerational learning practices - digital leaders in schools. Education and Information Technologies. doi:10.1007/s10639-014-9322-z.

Räisänen, T., Ypsilanti, A., Ropes, D., Vivas, A. B., Viitala, M., \& Ijäs, T. (2014). Examining the requirements for an intergenerational learning game. Education and Information Technologies. doi:10.1007/s10639014-9324-x.

Tatnall, A. (2014). ICT, education and older people in Australia: A socio-technical analysis. Education and Information Technologies. doi:10.1007/s10639-013-9300-х.

United States Department of Education (n.d.). Learning: Engage and Empower. No place of publication: U.S. Department of Education. Accessible at: http://www.ed.gov/technology/netp-2010/learning-engage-andempower. Accessed 9 May 2014.

Ypsilanti, A., Vivas, A. B., Räisänen, T., Viitala, M., Ijäs, T., \& Ropes, D. (2014). Are serious video games something more than a game? A review on the effectiveness of serious games to facilitate intergenerational learning. Education and Information Technologies. doi:10.1007/s10639-014-9325-9. 